\title{
Socio-demographic status and 12 years trend of completed suicide in East Azerbaijan Province, Iran, during the period 2007-2018
}

\author{
Mostafa Farahbakhsh', Maryam Nejad Asgari², Vahab Aslrahimi², Azam Hemmati², Ilnaz Iranzad $^{2}$ and \\ Hosein Azizi ${ }^{2,3^{*}}$ (D)
}

\begin{abstract}
Background: The incidence rate of suicide has been increased in Iran over the past decades especially in East Azerbaijan Province which there are limited studies on suicide. We aimed to investigate the 12-year trend of suicide and demographic characteristics in East Azerbaijan Province during the period 2007-2018. We obtained the data on the suicide mortality and socio-demographic status from the Death Registry Information System (DRIS) and compared with legal medicine suicide statistics during the study period.

Results: A total of 2422 and 1783 suicide cases were reported by legal medicine and DRIS (average incidence rate 5.94 vs 4.4 per 100,000) in the 12-year period from 2007 to 2018, respectively. The suicide rate in males was more than two times that of females. The mean and median age of suicide was 34.07 and 31 years, respectively. The most common suicide method was hanging (51.9\%). The incidence rate of suicide cases was decreasing between 2007 and 2014, however from 2015 to 2018 has been increased.
\end{abstract}

Conclusions: The incidence rate of suicide in this province has been increasing with a smooth slope. Communitybased programs and measures should be taken to stop the growth rate of suicide.

Keywords: Suicide, Incidence, Trend, East Azerbaijan

\section{Background}

Suicide has defined the act of intentionally self-killing [1, 2]. Suicide is an important and ongoing health concern around the world [3]. Annually, approximately 1 million people die due to suicide, yet in many settings, most suicide deaths go undetected and these numbers are the tip of the iceberg [2, 4]. Suicide rate is usually higher among developed and Eastern Europe and Eastern Meditation, and Islamic countries have lower suicide rates, due to

\footnotetext{
* Correspondence: azizih@razi.tums.ac.ir; aziziepid@gmail.com ${ }^{2}$ Research Center of Psychiatry and Behavioral Sciences, Tabriz University of Medical Sciences, Tabriz, Iran

${ }^{3}$ Department of Epidemiology and Biostatistics, School of Public Health,

Tehran University of Medical Sciences, Tehran, Iran

Full list of author information is available at the end of the article
}

many social and religious aspects and/or lack of effective registry for suicide systems $[5,6]$. However, based on standard mortality rates for suicide, low- and middleincome and high-income countries have similar rates at 11.2 and 12.7 per 100,000 people, respectively [7]. In fact, over $79 \%$ of global suicides occurred in low- and middle-income countries in 2016 and approximately $60 \%$ of the suicides occur in Asian countries [8]. It seems that suicide has come from Western Europe to Eastern Europe, and now Asia has become the heart of the problem [9].

World Health Organization (WHO) reported that the average rate of suicide in Iran is 5.3 per 100,000 people and across the provinces mortality rate of suicide ranged from 2.2 to 19.53 per 100,000 persons in 2012 which 
majority of suicides has occurred in men $(66 \%)[10,11]$. The high incident of suicides in both sexes were occurred in the adult age groups (16.1 per 100,000) that directly affect Years of Life Lost (YLL) and also Disability Adjusted Life Years (DALY) [11].

There are many important risk factors for completed suicide including psychiatric disorders, particularly depressive disorders, history of suicide attempts or suicidal behaviors, physical illnesses, and lack of social support and personality aspects $[12,13]$. In developed countries, more than $90 \%$ of suicide cases have some grade of mental illness, and among Asian countries including India and China, almost $60 \%$ of suicides have suffered from psychological disorders [10]. In Iran, the most common ways of suicide and suicide attempts are medication overdose or poisoning and hanging. However, the suicide method is different base on demographic characteristics including age, sex, and social or education level [14].

Researches on suicide have been broadly published in developed and industrialized settings; however, it is poorly understood among low- and middle-income countries especially in East Azerbaijan Province and Iran. In East Azerbaijan Province, there is a lack of studies on a better understanding of long-term suicide distribution and demographic situation. Moreover, advances in understanding local and up-to-date information about suicide trends and distributions in East Azerbaijan as a developing setting provide valuable information for the policymakers on need assessment and revising of the development strategies. Consequently, this study was aimed to investigate the 12-year trend and rate of suicide and demographic characteristics in East Azerbaijan Province during the period 2007-2018.

\section{Methods}

\section{Study design and setting}

This cross-sectional study was investigated all suicide deaths in East Azerbaijan Province during the period 2007-2018. Data were collected from the Death Registry Information System (DRIS), legal statistics, and the department of mental health for suicide surveillance systems. Legal medicine is a valid data source for any injury, factional, and criminal lethal in Iran. Suicide death was determined based on specialist legal medicine doctors after anatomic assessment and confirmation.

In the DRIS, all deaths, as well as suicide deaths, were collected from all over community-based health homes and health centers, hospitals, legal medicine, and cemeteries based on the same "death certificates" in each county and then all confirmed deaths included in the DRIS. The overlap cases were corrected in the province registry system. Demographic characteristics and population size data were obtained through the results of the general population census and DRIS. Moreover, we obtained numbers of suicide deaths from province legal medicine for comparing suicide rates between these two databases and reliability assessment of suicide deaths.

Morbidity of mental disorder was determined based on the electronic suicide registry system and the Health Integrated System (SIB). In this system, mental disorders screened by family physicians in the initial step and then confirmed by psychiatrists after psychiatric interview via structured tools.

\section{Data analysis}

Data were analyzed using SPSS (v. 19.0, Chicago, IL, USA) and EXEL 2013. Descriptive statistics and graphs were used to describe frequencies and ratios of suicide deaths. The incidence rate was calculated per 100,000 by years from the data on population from the statistical center of Iran.

\section{Results}

This study included 2422 and 1783 cases of suicide deaths in the 12-year period 2007-2018 in East Azerbaijan Province based on two vital statistic information systems including DRIS and legal medicine, respectively. The mean age of suicide cases was higher than the median age in all over the years. The overall mean age of all suicide cases was $34.07 \pm 15.68$ (range 7-92) years while the median age was 31 years (Fig. 1).

The majority of suicidal cases $1102(61.82 \%)$ were in the age group of 25-59 years while the lowest suicide distribution $59(3.33 \%)$ occurred in the age group below 14 years. The gender distribution for all suicide cases was $1204(67.5 \%)$ males, 1152 (64.63\%) were married, and $36.5 \%$ were unemployed. Likewise, more than $58 \%$ of participants had secondary school education, and almost $70 \%$ of those have occurred in urban settings. Moreover, out of those, $17.7 \%$, and $6.2 \%$ had a history of at least one psychiatric disorder and history of attempt, respectively (Table 1).

The completed suicidal rates by two different database systems including DRIS and legal medicine are shown in Table 2. Totally, suicide rates in legal medicine were higher than DRIS the all over years. The total number of suicide cases based on legal medicine and DRIS in the 12 -year period were 5.94 , and 4.4 per 100,000 in both genders, respectively. In both registry systems and all years of the study period, suicidal deaths were high among males. In both registry systems of legal medicine and DRIS, the highest rate in 2008 (8.42, and 6.17 per $100,000)$ and the lowest rate occurred in 2014 (3.78, and 2.7 per 100,000), respectively. Overall, the incidence trend of suicide in this province increasing from 2.7 in 2004 to 5.65 per 100,000 persons in 2018 .

Table 3 indicates suicide methods in the 12 years. The most common method of suicide was hanging 1058 


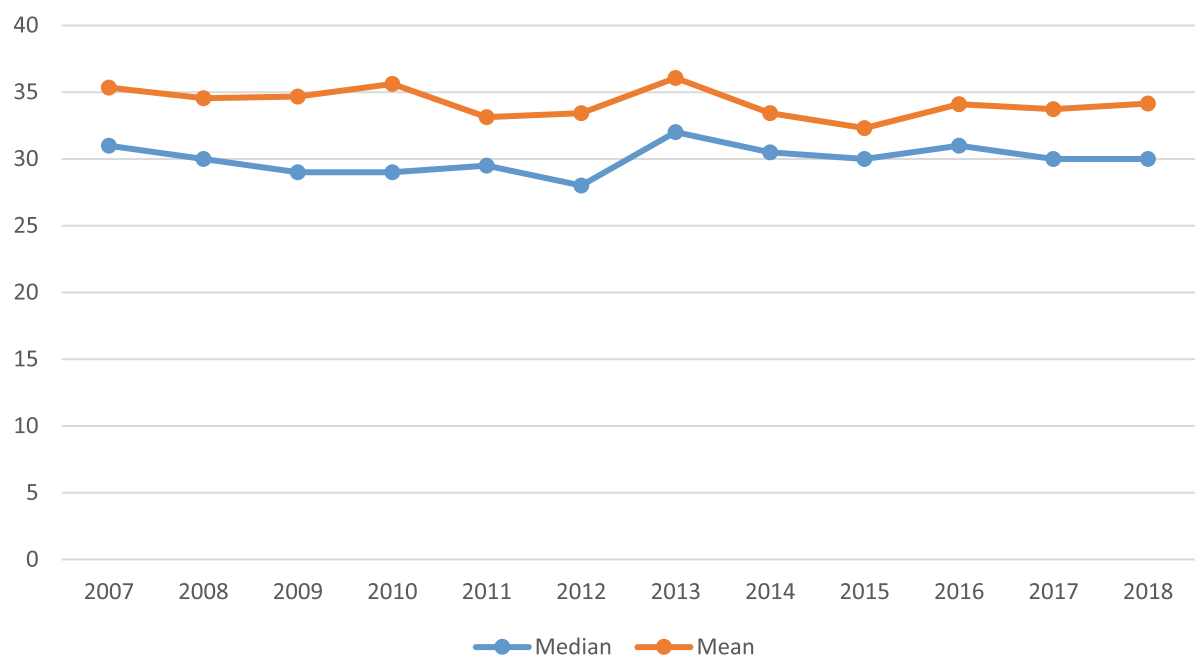

Fig. 1 Mean and median age of suicides in East Azerbaijan Province during 2007-2018 ( $P=0.027)$

(61.6\%) and poising or medication overdose methods $471(26.4 \%)$.

\section{Discussion}

This study investigates the rate of completed suicide in the general population in East Azerbaijan Province during the years 2007 to 2018, where there are limited documents about suicide. The trend of suicide cases was decreasing between 2007 and 2014, but from 2015 to 2018 has been increasing with a smooth slope. Totally, the incidence rate of suicide has increased slightly during the study period from 2007 to 2018 . The pattern of suicide trend in the present study is in line with the trend of all Iranian completed suicide cases reported by Razai et al. [10].

The incidence rate of suicide in males was higher than in females all over the years. The highest incidence rate was in men, 6.17 per 100000 in 2008. For females, the highest suicide rate was 2.16 per 100,000 in 2018. Our findings were congruent with other studies done in various provinces of Iran [15-17]. A systematic review and meta-analysis study in Iran revealed that western regions have shown the highest suicide rate 12.9 per 100,000 [18].

In this study, we compared suicide incidence trends via two valid registry-based systems including legal medicine and DRIS while most studies have only evaluated the trend of suicide through a single database. In this province, the incidence rates of suicide based on legal medicine were higher than DRIS around all years and there was a noticeable difference in the number of suicides between the two databases.

In the present study, 2422, and 1783 suicide cases ( total incidence rate 5.94 vs 4.4 per 100,000 ) were reported by legal medicine and DRIS in East Azerbaijan Province during the period 2007-2018, respectively.
Hajebi et al. found the incidence rate of suicide ranged from 1.76 to 2.23 per 100,000 persons among Iranian from 2009 to 2012 based on National Suicide Registration System [19]. Similar to the present study in Hajebi study and also a recently published study in 2021 by Mahdavi, the hanging was the most common suicide methods among all country suicide cases [20].

In the present study, the mean and median age of suicide death was 34.07 and 31 years, respectively and $67.5 \%$ were males, and $64.63 \%$ were married. The highest suicide rates were found in the age groups of 15-24 (26.21\%) and $25-59$ years $(61.82 \%)$, the majority of suicidal people used hanging (61.6\%) as the suicide method. Occupation distribution was (36.5\%) unemployment or free, and secondary education level was $58.1 \%$, and the urban setting was $69.2 \%$. Currently, a study in agreement with our study that performed based on the Iranian forensic medicine during 2016 and 2018 found that the median age of suicide cases was 31 years, and 30 to 59 age group was prevalent category and $71.2 \%$ were men [20].

The findings of the present study were in agreement with the study in Brazil, the incidence rate of suicide has increased from 5.84 per 100,000 persons in 2000 to 7.23 per 100,000 in 2015 and represents a 19\% increase in the incidence of suicide deaths over the period [13].

In the present study, males have committed suicide more than two times than females. According to the WHO report in 2016, the mortality rate by suicide in males has been about twice that of females [10]. Likewise, the male to female sex ratio was 1.4 in the Zhong study, and suicide in men has been observed $40 \%$ higher than in women [21]. In the study in Brazil from 1980 to 2009 , the male to female sex ratio was more than 4 times [22]. In the study by Sharafkhani et al. in Oromiya, Iran, the ratio of the odds of suicide steer to death in 
Table 1 Baseline characteristics of suicide deaths based on Death Registry Information System in East Azerbaijan Province, during 2007-2018

\begin{tabular}{|c|c|c|}
\hline Variable & Frequency $(n=1783)$ & $\%$ \\
\hline \multicolumn{3}{|l|}{ Gender } \\
\hline Female & 579 & 32.5 \\
\hline Male & 1204 & 67.5 \\
\hline \multicolumn{3}{|l|}{ Age } \\
\hline Mean \pm SD, (range) & $34.07 \pm 15.68,(7-92)$ & \\
\hline$\leq 14$ & 59 & 3.33 \\
\hline $15-24$ & 467 & 26.21 \\
\hline $25-59$ & 1102 & 61.82 \\
\hline$\geq 60$ & 144 & 8.1 \\
\hline \multicolumn{3}{|l|}{ Educational level } \\
\hline Primary school & 522 & 29.3 \\
\hline Secondary school & 1036 & 58.1 \\
\hline High school and Academic & 219 & 12.3 \\
\hline \multicolumn{3}{|l|}{ Resident } \\
\hline Urban & 1234 & 69.2 \\
\hline Rural & 549 & 30.8 \\
\hline \multicolumn{3}{|l|}{ Occupation } \\
\hline Free, and unemployment & 651 & 36.5 \\
\hline Student (school-university) & 225 & 12.6 \\
\hline Housewife & 464 & 26 \\
\hline Farming or farming related & 269 & 15.1 \\
\hline Employment & 55 & 3.1 \\
\hline Others & 119 & 6.7 \\
\hline \multicolumn{3}{|l|}{ Marital status } \\
\hline Single & 575 & 32.25 \\
\hline Married & 1152 & 64.63 \\
\hline Widow and divorced & 56 & 3.12 \\
\hline \multicolumn{3}{|l|}{ History of attempt } \\
\hline Yes & 111 & 6.2 \\
\hline No & 1637 & 91.8 \\
\hline \multicolumn{3}{|l|}{ History of mental disorder } \\
\hline Yes & 316 & 17.7 \\
\hline No & 1467 & 82.3 \\
\hline
\end{tabular}

males was 3 times higher than that of females [23]. However, in most findings, suicide attempts have been more prevalent among females. Using harsher and aggressive methods including the hanging methods and firearms are the main reasons for the significant difference in suicide mortality in males compared to females that increased fatal and decreased odds of survival. In contrast, females tend to medication overdose and poisoning that are fewer considered to be lethal [24].
Likewise, in the present study, more than $61 \%$ of participants used the hanging suicide method. Evidence indicates the use of violent and aggressive methods for suicide growths the hazard of completed suicide 12 times [10]. Drug and substance abuse and also mentalneurological problems are other reasons for high suicide rates among males [25]. The same results were found in the USA and Brazil that $72 \%$ of suicide cases were committed using firearms $[13,26]$. Despite that, hanging is the most commonly used suicide method globally; however, the distribution of the methods is diverse among various settings.

In the recent decade, the concern of suicide death has shifted from developed and industrialized countries and now to Asia [27]. Decreasing social and mental health supports and also social happiness, alterations in the family and community habits and customs are the most important factors in rising of suicide and suicidal behaviors over the last year s[10]

In the present study, the majority of suicidal cases were observed in the age groups of 25-59 and 15-25 years, which were consistent with the results of previous studies $[16,28,29]$. This shows the essence of paying attention to this group of people, as they are the productive generation of the community. The suicidal behaviors distribution and correlated factors in the age group of 15-29 years have been the focus of various studies, proposing the role of family conflicts and divorce, disturbing hormonal fluctuations and mental health status, and access to the firearm as the main elements for the high incidence rate in this people [3, 30]. In Iran, one of the factors that belong in the event of Konkoor as a national university entrance exam that imposes great pressure on Iranian adolescences at this age group, and the higher suicidal behaviors incident in June and July might also be attributed to the same event [31].

Comparing the incidence rate of the present study with other studies shows that the suicide mortality in East Azerbaijan Province is lower than most European countries and the USA [32, 33] and also lower than in Eastern Provinces of Iran including Ilam [34]; however, it is slightly higher than whole country suicide mortality rates which shows the necessity to pay attention to this social concern issue in this province, as the fourth populous province of Iran.

\section{Strengths and limitations}

The main strength of this study is using two valid suicide registry-based systems including legal medicine and DRIS to prevent the possibility of underreporting which rare studies focused on. Nevertheless, this study had limitations. First, we did not calculate age standard mortality rates; however, the age 
Table 2 Comparison of suicide rates between legal medicine statistics and Death Registry Information System in East Azerbaijan Province during the period 2007-2018

\begin{tabular}{|c|c|c|c|c|c|c|c|}
\hline \multirow[t]{2}{*}{ Years } & \multirow[t]{2}{*}{ Population } & \multicolumn{2}{|c|}{ Legal medicine } & \multicolumn{4}{|c|}{ Death registry system } \\
\hline & & $\mathrm{N}$ & Rate & $\mathrm{N}$ & Total rate & Female & Male \\
\hline 2007 & 3263637 & 248 & 7.60 & 184 & 5.63 & 2.11 & 4.27 \\
\hline 2008 & 3289747 & 277 & 8.42 & 203 & 6.17 & 2.05 & 5.02 \\
\hline 2009 & 3296587 & 175 & 5.31 & 131 & 3.97 & 1.48 & 2.83 \\
\hline 2010 & 3358849 & 202 & 6.01 & 151 & 4.5 & 1.87 & 3.88 \\
\hline 2011 & 3301616 & 186 & 5.63 & 139 & 4.21 & 1.69 & 3.23 \\
\hline 2012 & 3334491 & 194 & 5.82 & 142 & 4.26 & 1.56 & 3.46 \\
\hline 2013 & 3400618 & 168 & 4.94 & 121 & 3.56 & 1.38 & 2.77 \\
\hline 2014 & 3408425 & 129 & 3.78 & 92 & 2.7 & 1.25 & 2.09 \\
\hline 2015 & 3526045 & 159 & 4.51 & 120 & 3.4 & 1.41 & 2.64 \\
\hline 2016 & 3506581 & 183 & 5.22 & 137 & 3.9 & 1.57 & 2.57 \\
\hline 2017 & 3518990 & 227 & 6.45 & 161 & 4.57 & 1.74 & 3.43 \\
\hline 2018 & 3572038 & 274 & 7.67 & 202 & 5.65 & 2.16 & 4.18 \\
\hline Total & & 2422 & 5.94 & 1783 & 4.40 & 1.52 & 3.26 \\
\hline
\end{tabular}

distribution in this province and age categories are similar to the age distribution of the national population and there are no differences between those.

Second, we used only one data source (DRIS source) for presenting study results due to the unavailability and inaccessibility of participant's characteristics and ethical limitations of suicide cases in legal medicine.

\section{Conclusion}

A total of 2422 and 1783 suicide cases (average incidence rate 5.94 vs 4.4 per 100,000 ) were reported by legal medicine and DRIS in East Azerbaijan Province during the period 2007-2018. The incidence rates of suicide based on legal medicine were higher than DRIS. Overall, the incidence rate of suicide in this province has been increasing with a smooth slope so that it was increased from 2.7 in 2014 to 5.65 per 100,000 persons in 2018. Considering the increasing trend of suicide rates in East Azerbaijan Province, community-based programs and measures should be taken to suicide prevention.

Table 3 Methods of suicide deaths in East Azerbaijan Province based on DRIS during the period 2007-2018

\begin{tabular}{lll}
\hline Suicide methods & $\mathbf{N = 1 7 8 3}$ & \% \\
\hline Hanging & 1098 & 61.6 \\
Poisoning or medications & 471 & 26.4 \\
Self-injury & 125 & 7 \\
Fall & 39 & 2.2 \\
Self-immolation & 30 & 1.7 \\
Others or unknown & 14 & 0.8 \\
\hline
\end{tabular}

Abbreviation

DRIS: Death Registry Information System

\section{Acknowledgements}

We express our gratitude to our colleagues in "Research Center of Psychiatry and Behavior Sciences" and Center for clinical research development, Razi

Psychiatric Hospital, Tabriz University of Medical Sciences.

\section{Authors' contributions}

MF and HA: concept and design. MN and MF: data collection and interpretation of the data. VA, MN, AH, and II performed the study and analysis. HA and MF: writing of the draft. All authors read and approved the study.

\section{Funding}

This study was funded completely by the Tabriz University of Medical Sciences, Tabriz, Iran.

\section{Availability of data and materials}

The datasets used and/or analyzed during the current study are available from the corresponding author on reasonable request.

\section{Declarations}

\section{Ethics approval and consent to participate}

This study was approved by ethics committee of Tabriz University of Medical Sciences to number: IR.TBZMED.REC.1398.870. The present study was derived from the MD thesis and no human samples were investigated or interviewed.

\section{Consent for publication}

Not applicable

\section{Competing interests}

The authors declare that there is no conflict of interest and financial disclosure.

\section{Author details}

${ }^{1}$ Road Traffic Injury Research Center, Tabriz University of Medical Sciences, Tabriz, Iran. ${ }^{2}$ Research Center of Psychiatry and Behavioral Sciences, Tabriz University of Medical Sciences, Tabriz, Iran. ${ }^{3}$ Department of Epidemiology 
and Biostatistics, School of Public Health, Tehran University of Medical Sciences, Tehran, Iran.

Received: 2 April 2021 Accepted: 18 May 2021

Published online: 07 July 2021

\section{References}

1. Hassan WA, Noaman MM, Khalifa H, Abdelrahman AA, Omar SM (2020) A clinical study of suicide in patients admitted in psychiatry unit in Assiut University. Middle East Curr Psychiat 27(1):1-8

2. Santos $A D$, Guimarães LML, Carvalho YF, Viana LC, Alves GL, Lima ACR, Santos MB, Góes MAO, Araújo KCGM (2018) Spatial analysis and temporal trends of suicide mortality in Sergipe, Brazil, 2000-2015. Trends Psychiat Psychother 40(4):269-276. https://doi.org/10.1590/2237-6089-2017-0028

3. Wasserman $D$, Cheng $Q$, Jiang G-X (2005) Global suicide rates among young people aged 15-19. World Psychiatry 4(2):114-120

4. Azizi H, Farahbakhsh M, Fakhari A, Esmaeili ED, Mirzapour M, Aslrahimi V, Barzegar H (2021) Effective programs and strategies on suicide prevention: combination of review of systematic reviews with expert opinions. Int J Prev Med in Press

5. Farahbakhsh M, Fakhari A, Davtalab Esmaeili E, Azizi H, Mizapour M, Asl Rahimi V, Hashemi L (2020) The role and comparison of stressful life events in suicide and suicide attempt: a Descriptive-Analytical Study. Iran J Psychiat Behav Sci 14(2):e96051. https://doi.org/10.5812/ijpbs.96051

6. Conwell Y, Van Orden K, Caine ED (2011) Suicide in older adults. Psychiatr Clin 34(2):451-468. https://doi.org/10.1016/j.psc.2011.02.002

7. Pollock NJ, Naicker K, Loro A, Mulay S, Colman I (2018) Global incidence of suicide among Indigenous peoples: a systematic review. BMC Med 16(1):1-17

8. Hossain HUAD, Aftab A, Soron TR, Alam MT, Chowdhury MWA, Uddin A (2017) Suicide and depression in the World Health Organization South-East Asia region: A systematic review. WHO South-East Asia J Public Health 6(1): 60-66

9. Chen Y-Y, Chien-Chang Wu K, Yousuf S, Yip PS (2012) Suicide in Asia: opportunities and challenges. Epidemiol Rev 34(1):129-144. https://doi.org/1 0.1093/epirev/mxr025

10. Razai D, Ghadirzadeh MR, Mahdavi SA, Hasani J, Nazari SSH (2020) The suicide rate in the elderly population of Iran between 2008 and 2014. J Res Health Sci 20(1):e00471. https://doi.org/10.34172/jrhs.2020.06

11. WHO (2014) Preventing suicide: a global imperative. Geneva: World Health Organization

12. Liu B-P, Qin P, Jia C-X (2018) Behavior characteristics and risk factors for suicide among the elderly in rural China. J Nerv Ment Dis 206(3):195-201. https://doi.org/10.1097/NMD.0000000000000728

13. Duarte SKM, Hillesheim D (2021) Hallal ALdLC: Temporal trend of mortality by suicide among adults in Brazil: 2000 to 2015. Trends Psychiat Psychother 43(1):65-71. https://doi.org/10.47626/2237-6089-2020-0009

14. Shojaei A, Moradi S, Alaeddini F, Khodadoost M, Ghadirzadeh MR, Khademi A (2013) The association between completed suicides and season of the year in an Iranian population. Iran J Public Health 42(3):293-297

15. Mokhtari AM, Sahraian S, Hassanipour S, Baseri A, Mirahmadizadeh A (2019) The epidemiology of suicide in the elderly population in Southern Iran, 2011 2016. Asian J Psychiatr 44:90-94. https://doi.org/10.1016/j.ajp.2019.07.027

16. Mirahmadizadeh A, Rezaei F, Mokhtari AM, Gholamzadeh S, Baseri A (2020) Epidemiology of suicide attempts and deaths: a population-based study in Fars, Iran (2011-16). J Public Health 42(1):e1-e11. https://doi.org/10.1093/ pubmed/fdy218

17. Khorshidi A, Sayehmiri K, Babanejad M (2014) Seasonality of suicide occurrence in Ilam. Iran J Epidemiol 9(3):17-23

18. Daliri S, Bazyar J, Sayehmiri K, Delpisheh A, Sayehmiri F (2017) The incidence rates of suicide attempts and successful suicides in seven climatic conditions in Iran from 2001 to 2014: a systematic review and meta-analysis. Sci J Kurdistan Univ Med Sci 21(6):1-15

19. Hajebi A, Ahmadzad-Asl M, Davoudi F, Ghayyomi R (2016) Trend of suicide in Iran during 2009 to 2012: Epidemiological evidences from national suicide registration. Iran J Psychiat Behav Sci 10(4):e4398. https://doi.org/1 0.17795/ijpbs-4398

20. Mahdavi SA, Rezaeian S, Rostami M (2020) Profile of fatal suicide in Iran: A report from the Iranian forensic medicine between 2016 and 2018. Acta Med Iran 58(10):508-512
21. Zhong B-L, Chiu HF, Conwell Y (2016) Rates and characteristics of elderly suicide in China, 2013-14. J Affect Disord 206:273-279. https://doi.org/10. 016/j.jad.2016.09.003

22. Pinto LW (2012) Pires TdO, Silva CMFPd, Assis SGd: Suicide mortality temporal trends in people aged 60 years or more in the Brazilian states: 1980 to 2009. Ciencia Ssaude Coleta 17(8):1973-1981. https://doi.org/10.1 590/S1413-81232012000800008

23. Sharafkhani R, Biranvand A, Gareaghaji R (2013) Risk factors for death in suicide attempters-west Azerbaijan province: case-control study. Stud Med Sci 23(6):655-660

24. Shojaei A, Moradi S, Alaeddini F, Khodadoost M, Barzegar A, Khademi A (2014) Association between suicide method, and gender, age, and education level in I ran over 2006-2010. Asia Pacific Psychiat 6(1):18-22. https://doi.org/10.1111/appy.12097

25. Zarenezhad M, Gorgi Z, Sheikh Fathollahi M, Gholamzadeh S, Ghadipasha M, Rezaeian M (2015) Epidemiological survey of suicide in Fars Province in the south of Iran during 2003 to 2011. J Rafsanjan Univ Med Sci 13(12):11291140

26. Conwell Y, Thompson C (2008) Suicidal behavior in elders. Psychiat Clin North Am 31(2):333-356. https://doi.org/10.1016/j.psc.2008.01.004

27. Tandon R, Nathani MK (2018) Increasing suicide rates across Asia-a public health crisis

28. Najafi F, Hasanzadeh J, Moradinazar M, Faramarzi H, Nematollahi A (2013) An epidemiological survey of the suicide incidence trends in the southwest Iran: 2004-2009. Int J Health Policy Manag 1(3):219-222. https://doi.org/10.1 5171/ijhpm.2013.40

29. Yang X, Feldman MW (2018) A reversed gender pattern? A meta-analysis of gender differences in the prevalence of non-suicidal self-injurious behaviour among Chinese adolescents. BMC Public Health 18(1):1-7

30. Calegaro VC, Zatti C, Bastos AG, Freitas LHM (2019) Suicidal patients in a psychiatric emergency unit: clinical characteristics and aggression profile. Trends Psychiat Psychother 41(1):9-17. https://doi.org/10.1590/2237-6089-2 017-0149

31. Suchman MC (1995) Managing legitimacy: Strategic and institutional approaches. Acad Manag Rev 20(3):571-610. https://doi.org/10.5465/amr.1 995.9508080331

32. Värnik A, Kölves $K$, van der Feltz-Cornelis CM, Marusic A, Oskarsson $H$, Palmer A, Reisch T, Scheerder G, Arensman E, Aromaa E (2008) Suicide methods in Europe: a gender-specific analysis of countries participating in the "European Alliance Against Depression". J Epidemiol Community Health 62(6):545-551. https://doi.org/10.1136/jech.2007.065391

33. Spicer RS, Miller TR (2000) Suicide acts in 8 states: incidence and case fatality rates by demographics and method. Am J Public Health 90(12): 1885-1891. https://doi.org/10.2105/ajph.90.12.1885

34. Veisani Y, Delpisheh A, Mohamadian F, Valizadeh R (2018) Trends of suicide attempts and completed suicide in llam province of Iran; a demographic analysis study. Bull Emerg Trauma 6(3):245-248. https://doi.org/10.29252/bea $\mathrm{t}-060310$

\section{Publisher's Note}

Springer Nature remains neutral with regard to jurisdictional claims in published maps and institutional affiliations.

\section{Submit your manuscript to a SpringerOpen ${ }^{\circ}$ journal and benefit from:}

- Convenient online submission

- Rigorous peer review

- Open access: articles freely available online

- High visibility within the field

- Retaining the copyright to your article

Submit your next manuscript at $>$ springeropen.com 